\title{
The Challenge of Teaching Introductory Physics to Premedical Students
}

\author{
Gerd Kortemeyer \\ Lyman-Briggs School of Science \\ Michigan State University \\ East Lansing, MI 48825 \\ USA \\ Phone: (517) 282-6446 \\ Email:korte@lite.msu.edu \\ PACS 01.40.Di, 01.40.Fk, 01.40gb
}

\begin{abstract}
Most physics instructors are motivated by a genuine interest in their subject area and in using physics to understand real world phenomena. While many premeds may share these interests, most are motivated by fulfilling their degree requirements and gaining admittance into medical school. To achieve this goal, they usually need excellent grades. In addition, they have to do well on the physical sciences section of the Medical College Admissions Test (MCAT) ${ }^{1}$. Only too often, both sides just give up, and courses come to some kind of unspoken agreement of how to go through the motions of the course with the least amount of mutual aggravation, while real physics falls by the wayside. But how exactly does this discrepancy manifest itself, and what - if anything other than giving up - can be done about it? In this paper, we first survey learner beliefs, expectations and preferences, and then attempt to point out approaches and resources that may partly address the identified issues.
\end{abstract}

\section{Student Surveys}

We administered two surveys in a calculus-based introductory physics class taught by the author with a majority of premedical students:

- the quantitative Maryland Physics Expectations Survey (MPEX) ${ }^{2}$, which has a number of statements that students are asked to rate on a Likert scale. The MPEX aims to explore students' expectations and beliefs about the nature of physics

- a course-specific survey that aims to explore student preferences about how the course should be taught. It includes both quantitative and qualitative elements

The MPEX was administered twice: once at the beginning and once at the end of the first semester of the course. The data does not include whether or not a respondent is pursuing a career in a medical field, but, since the majority of the students in the course are premeds, still provides some insights into how premeds view physics. In the first column of Table I, we show a selection of statements from the MPEX, and in its second column, whether the majority of an expert panel agreed or disagreed with those statements ${ }^{2}$. The next columns show the response distribution of the students in our course both on the pre- and the post-MPEX. A student response is considered favorable if it corresponds to the majority of the expert panel, and unfavorable if it states the opposite. A neutral answer is neither favorable nor unfavorable. For example, it is unfavorable to 
agree with the statement "All I learn from a derivation or proof of a formula is that the formula is valid and it is OK to use it in problems," since the majority of the expert panel disagreed.

These sample responses correspond well with the experience most any physics instructor would have made: a recipe rather than conceptual approach to physics, e.g., derivations are not seen as a way to connect concepts, but as a way to prove that a formula is true, and solving problems boils down to plug-and-chug. The pre-survey results would be less depressing if instruction had actually made a significant difference, but it apparently does not. Even worse, the responses to item 11 show that the number of students who believe that physics is relevant for their career goals decreased over the course of the semester.

The MPEX is usually not analyzed on a per-question base, but instead in question clusters, which address different student characteristics. In Table II, the percentage of favorable responses in the clusters is given for both the pre- and the post-test, as well as comparison data from a course with mostly engineering students at the University of Maryland ${ }^{1}$.

In our course of mostly premeds the view of physics is generally less expert-like than in the comparison course. The largest difference occurs in the perception of the role of mathematics in physics. The least difference occurs in the concept cluster, where the premedical students are actually doing slightly better than the engineering students on the post survey.

In the second survey on the last day of the course, students were asked to state their preferences for how the course should be taught. The survey included both quantitative (Likert scale) response items and qualitative (open ended free form) questions.

Table III lists the quantitative items, which the students were asked to rank on a scale from 1 (strongly against) to 5 (strongly preferred). While trends are clearly visible for all items, the response distribution was so wide that only one option was not ranked within standard deviations of "neutral:" the preference of premedical students for medicine-related examples. As expected, non-premeds are less in favor of premed-specific items, but the error boundaries include neutral, which may be interpreted as not liking but tolerating these changes to the course

The qualitative analysis of the free-form responses was more revealing: the vast majority of premed students wrote that more examples from medicine and better MCAT preparation would have made the course more relevant to them.

Many premed students expressed an interest in medical imaging, followed by anatomical examples and more examples related to blood flow. It is interesting to note that these were exactly the areas in which examples were already given in lecture, giving rise to the assumption that, in most cases, the students did not see connections between physics and medicine other than the few already explicitly pointed out over the course of the year. The non-premeds stated that they could tolerate a fair amount of medical examples, and in fact, that it might be interesting to see such applications, as long as they do not take away from the physics they are learning, and as long as they do not become the focus of the course. The non-premeds however clearly and even somewhat aggressively stated that what they could not tolerate was MCAT preparation. The MCAT is clearly seen by non-premeds as a problem that the premeds have brought upon themselves.

Regarding the beliefs and expectations, the free-form responses also yielded differences between premeds and non-premeds. For example, the exams were open note, and premeds remarked that they "would have memorized the material more if the exams were not open note," indicating that 
memorization should be a goal of the course. Also, a call for "more examples with numbers instead of so many with only symbolic [representation]" was frequent among premeds, reflecting the belief that physics is about numbers. Finally, there were frequent remarks by the premeds that nothing should be derived, one time with the additional comment, "really, you have a Ph.D. I'll believe what you tell me" - suggesting, just like the MPEX responses, that the derivations are presented to prove that a formula is correct. None of these striking comments were found in the responses of non-premeds.

\section{What is the root of the problem?}

As the surveys are indicating, premedical students are approaching physics differently than, for example, engineering majors, and very differently than their instructors:

- The role of mathematics and formulas in physics. Here, the students appear to be unaware of their un-expert-like view of physics and instead criticize the style of instruction.

- The link to reality: the results of the MPEX indicate that over the course of the semester, the perceived relevance of physics actually decreases. The students are aware of this discrepancy and ask for more examples with medical topics.

Regarding the role of mathematics and formulas, the discrepancy is nicely described in an experience report about teaching physics to premeds by Nichparenko ${ }^{3}$ : "Two conflicting needs arose for our physics course to fill. The dreaded MCAT looms above the students. Nearly all agree that rote memory of formulas is most valuable for whipping out multiple choice answers, about one per minute, to finish the test. Yet everyone who goes on to use physics, student or teacher, agrees that concepts outrank plug-in equations by a huge margin." In other words, students actually have to plug-and-chug in order to succeed on the MCAT. Interestingly enough the physics questions on the MCAT have no connection to medicine or even biology - instead, they are frequently of the standard a-mass-of- $45-\mathrm{kg}$-is-accelerated-at-5-m/ $/ \mathrm{s}^{2}$-type, which is regrettable, since student perceptions of physics are in general strongly influenced by the assessment tools ${ }^{4}$. In the same paper, Nichparenko reports how practicing physicians often expressed regret over not having learned more physics. Contrary to the student responses in the MPEX Reality Link Cluster, physics simply is relevant for a physician.

\section{What can be done}

The misperceptions regarding the role of mathematics and formulas are serious, but also hard to overcome. It is common for students to see formulas in a purely operational sense ${ }^{5}$, even among majors ${ }^{6}$, while lacking the ability to translate between the formulas and the situations ${ }^{7}$. This is particularly distressing, since indications exist that mathematical and conceptual understanding of physics are connected ${ }^{8}$.

The pre- and post-MPEX results showed that mathematically deriving physics principles and modeling good problem solving strategies in the classroom did little good in bringing about change - actually, quite the opposite, the students resented these efforts without seeing immediate advantage to them. What is important to an instructor needs to be reflected in the assessments that he or she uses ${ }^{4}$, and the author attributes the partial success in the MPEX Concept Cluster to already having replaced a fraction of the standard numerical answer problems by conceptual problems. The hope is that replacing even more of these textbook-style problems with problems that expect representation translation and symbolic answers will bring about improvements in the Math Link Cluster. The ideal way would be the introduction of hand-graded free-form 
assessments, but that approach is limited to a small number of assignments for large enrollment courses with little grading support. As a substitute, computer-graded homework with symbolic answers and an increased number of questions or follow-up questions of the type "What will happen if this doubles?" could be assigned.

Regarding the reality link, student perceptions actually worsened after instruction. Here, the importance of examples from the medical field is reflected in the student survey. There are a number of existing textbooks on the undergraduate level addressing the connection between physics and medicine or life science. These are not necessarily intended to be used as textbook for the course, but as reference for the instructor:

Introductory Texts:

- Joseph Kane and Morton M. Sternheim, General Physics (formerly Life Science Physics) ${ }^{9}$ : this is a complete textbook incorporating examples such as nerve conduction, MRIs, radiation in medicine, EKG, etc. It is very well written and otherwise takes a standard approach to teaching introductory physics with an appropriate topic selection.

- Jerry Marion, General Physics with Bioscience Essays ${ }^{10}$ : similar to Kane and Sternheim, a standard introductory textbook. Twenty-seven essays on biological and medical topics are embedded into the chapters, each of which providing some contextual problems.

Advanced Texts:

- George Benedek and Felix Villars, Physics with Illustrative Examples from Medicine and Biology ${ }^{11}$ : this series is a comprehensive treatment of the physics involved in biological processes and medicine, but not an introductory physics book that can be used in a nonmajors course. The series is very mathematical and fun to read for a physicist, but definitely not suited as a textbook for students in introductory courses.

- Russell Hobbie, Intermediate Physics for Medicine and Biology ${ }^{12}$ : this is an authoritative textbook, less mathematically oriented than Benedek and Villars, but also not intended to be used in an introductory course. It provides a wide range of application examples.

Supplemental Material:

- Paul Davidovits, Physics in Biology and Medicine (Complementary Science) ${ }^{13}$ : this booklet offers short reviews of some basic physics concepts, approximately 70 applications in biology and medicine, and related homework problems. Though the level is somewhat below that of a calculus-based introductory physics course, instructors might still find value in requiring this booklet for their students.

In order to give an idea of the scope of topics in these texts, as well as additional topics identified by Hobbie ${ }^{14,15}$, Table IV has been included.

\section{Conclusion}

The disconnect between physics teachers and their premed students has its roots in different expectations. Where instructors seek to impart concepts from which students can draw understanding, premeds hold a mostly non-expert-like view of what physics is about. Instead, they are motivated by their need to perform on standardized tests with mostly formula-driven numerical problems, and by the need to get a very good grade in a course that seems foreign and unintuitive to them. The results of the surveys would seem to recommend frequent examples of 
medical topics in premed courses, in addition to grade-relevant assessment in the course focusing more on conceptual solutions and problem solving strategy. The real diplomacy would be in convincing the students that there are hardly any textbook problems with numerical solutions in real life, and that physicians need a deeper level of understanding of physics. The results also appear to indicate that in mixed courses, non-premeds are likely going to tolerate examples from medicine, but definitely will not tolerate turning introductory physics courses into MCAT preparation courses.

\section{References}

1. American Association of Medical Colleges, "Medical College Admission Test", http://www.aamc.org/students/mcat/

2. E. F. Redish, R. N. Steinberg, and J. M. Saul, "Maryland Physics Expectations Survey" in "Student expectations in introductory physics," American Journal of Physics 66, 212 (March 1998)

3. S. B. Nichparenko, "Premed physics: what and why," Journal of College Science Teaching 14, 391 (April 1985)

4. H. Lin, “Learning physics vs. passing courses,” The Physics Teacher 20, 151 (March 1982)

5. E. Torigoe,, "Student difficulties with equations in physics," ISAAPT Spring Meeting, Urbana, IL (2004)

6. E. Breitenberger, "The mathematical knowledge of physics graduates: Primary data and conclusions," American Journal of Physics 60, 318 (April 1992)

7. J. Clement, J. Lochhead, and G. S. Monk, "Translation difficulties in learning mathematics, Amer. Math. Mon. 88, 286 (April 1981)

8. D. Meltzer, "The relationship between mathematics preparation and conceptual learning gains in physics: a possible 'hidden variable' in diagnostic pretest scores," American Journal of Physics, 70, 1259 (December 2002)

9. J. Kane and M. Sternheim, “General Physics," ISBN 0471533783 (John Wiley and Sons, New York, Santa Barbara, Chichester, Brisbane, Toronto, 1991)

10. J. Marion, "General Physics with Bioscience Essays,” ISBN 047156911 (John Wiley and Sons, New York, Chichester, Brisbane, Toronto, 1979)

11. G. B. Benedek and F. M. H. Villars, "Physics with Illustrative Examples from Medicine and Biology (Series)," ISBN 038798769X (Mechanics) and ISBN 0387987703 (E\&M) (Springer Verlag, New York, Berlin, Heidelberg, 2000)

12. R. K. Hobbie, "Intermediate Physics for Medicine and Biology," ISBN 1563964589 (Springer Verlag, New York, Berlin, Heidelberg, 1997)

13. P. Davidovits, "Physics in Biology and Medicine (Complementary Science)," ISBN 0122048407 (Academic Press, 2001) 
14. R. K. Hobbie, "Physics useful to a medical student," American Journal of Physics 42, 121 (February 1977)

15. R. K. Hobbie, "Resource Letter MP-1: Medical Physics," American Journal of Physics 53, 822 (September 1985) 


\section{Table I}

\begin{tabular}{|c|c|c|c|c|c|}
\hline & & \multicolumn{2}{|c|}{ Beginning (Pre) } & \multicolumn{2}{|c|}{ End (Post) } \\
\hline Statement & Expert & Favorable & $\begin{array}{c}\text { Un- } \\
\text { favorable }\end{array}$ & Favorable & $\begin{array}{c}\text { Un- } \\
\text { favorable }\end{array}$ \\
\hline $\begin{array}{l}\text { (2) All I learn from a } \\
\text { derivation or proof of a } \\
\text { formula is that the formula is } \\
\text { valid and it is OK to use it in } \\
\text { problems }\end{array}$ & Disagree & $22 \%$ & $42 \%$ & $32 \%$ & $40 \%$ \\
\hline $\begin{array}{l}\text { (11) A good understanding of } \\
\text { physics is necessary for me to } \\
\text { achieve my career goals. A } \\
\text { good grade in this course is not } \\
\text { enough. }\end{array}$ & Agree & $43 \%$ & $28 \%$ & $36 \%$ & $34 \%$ \\
\hline $\begin{array}{l}\text { (14) Learning physics is a } \\
\text { matter of acquiring knowledge } \\
\text { that is specifically located in } \\
\text { the laws, principles, and } \\
\text { equations given in class and/or } \\
\text { in the textbook }\end{array}$ & Disagree & $23 \%$ & $43 \%$ & $29 \%$ & $48 \%$ \\
\hline $\begin{array}{l}\text { (19) The most crucial thing in } \\
\text { solving a physics problem is } \\
\text { finding the right equation to } \\
\text { use. }\end{array}$ & Disagree & $17 \%$ & $57 \%$ & $18 \%$ & $45 \%$ \\
\hline
\end{tabular}




\section{Table II}

\begin{tabular}{|l|l|l|l|l|l|}
\hline Cluster & Student Characteristic & $\begin{array}{l}\text { Premed } \\
\text { Pre }\end{array}$ & $\begin{array}{l}\text { Premed } \\
\text { Post }\end{array}$ & $\begin{array}{l}\text { Engineering } \\
\text { Pre }\end{array}$ & $\begin{array}{l}\text { Engineering } \\
\text { Post }\end{array}$ \\
\hline Independence & $\begin{array}{l}\text { Takes responsibility for } \\
\text { constructing own knowledge }\end{array}$ & $37 \%$ & $42 \%$ & $59 \%$ & $58 \%$ \\
\hline Coherence & $\begin{array}{l}\text { Believes physics needs to be } \\
\text { considered as connected, } \\
\text { consistent framework }\end{array}$ & $40 \%$ & $46 \%$ & $57 \%$ & $61 \%$ \\
\hline Concepts & $\begin{array}{l}\text { Stresses understanding of the } \\
\text { underlying ideas and concepts }\end{array}$ & $44 \%$ & $48 \%$ & $45 \%$ & $46 \%$ \\
\hline Reality Link & $\begin{array}{l}\text { Believes ideas learned in } \\
\text { physics are relevant and } \\
\text { useful in a wide variety of } \\
\text { real contexts }\end{array}$ & $67 \%$ & $55 \%$ & $72 \%$ & $69 \%$ \\
\hline $\begin{array}{l}\text { Considers mathematics as a } \\
\text { convenient way of } \\
\text { representing physical } \\
\text { phenomena }\end{array}$ & $42 \%$ & $40 \%$ & $72 \%$ & $72 \%$ \\
\hline $\begin{array}{l}\text { Makes the effort to use } \\
\text { information available and } \\
\text { tries to make sense of it. }\end{array}$ & $59 \%$ & $47 \%$ & $72 \%$ & $63 \%$ \\
\hline
\end{tabular}




\section{Table III}

\begin{tabular}{|l|l|l|}
\cline { 2 - 3 } \multicolumn{1}{c|}{} & Premeds & Non-Premeds \\
\hline Number of Responses & 37 & 18 \\
\hline Application examples of physics in medicine & $4.2+/-1$ & $2.4+/-1.2$ \\
\hline Homework problems with medical relevance & $3.9+/-1$ & $2.2+/-1.2$ \\
\hline In-class exercises with medical relevance & $3.7+/-1$ & $2.2+/-1.1$ \\
\hline Guest speaker from the medical field & $3.9+/-1.4$ & $1.8+/-1.2$ \\
\hline
\end{tabular}


Table IV

\begin{tabular}{|c|c|}
\hline First Semester & Second Semester \\
\hline $\begin{array}{l}\text { - Energy and Work } \\
\circ \quad \text { Scaling with body size } \\
\text { - Momentum and Collisions } \\
\circ \text { Whiplash injury } \\
\text { - Rotational Kinematics; Rotational } \\
\text { Dynamics } \\
\circ \quad \text { Muscles } \\
\text { - Temperature, Solids, Liquids and Gases } \\
\bigcirc \quad \text { Artery plague } \\
\bigcirc \quad \text { Aneurysms } \\
\bigcirc \quad \text { Blood pressure } \\
\bigcirc \quad \text { Bones and bone fractures } \\
\text { - Waves and Sound } \\
\bigcirc \quad \text { Ultrasound imaging } \\
\bigcirc \quad \text { Extracorporeal shock wave } \\
\text { lithotripsy } \\
\circ \text { The human ear } \\
\text { - Heat; Thermodynamics } \\
\bigcirc \quad \text { Metabolism }\end{array}$ & $\begin{array}{c}\text { - Electrostatics; Electric Field } \\
\circ \quad \text { Membrane equilibrium } \\
\text { - Capacitors } \\
\circ \text { Defibrillators } \\
\text { - Current } \\
\circ \text { Neurons } \\
\circ \quad \text { The axon } \\
\text { - Magnetism; Induction } \\
\circ \quad \text { Magnetocardiogram } \\
\text { - Time-Varying Currents } \\
\circ \quad \text { Pacemaker } \\
\circ \quad \text { Electrocardiogram } \\
\text { - Electromagnetic Waves } \\
\text { - Mirrors and Lenses; Optical } \\
\text { Instruments } \\
\circ \quad \text { The human eye } \\
\circ \quad \text { Corrective lenses } \\
\circ \quad \text { Laser eye surgery } \\
\circ \quad \text { Endoscopes } \\
\text { - Interference and Diffraction } \\
\circ \quad \text { Limitations to medical } \\
\quad \text { imaging } \\
\text { - Quantum Theory } \\
\circ \quad \text { Fluoroscopy } \\
\circ \quad \text { Electron microscope } \\
\circ \quad \text { Magnetic resonance imaging } \\
\circ \quad \text { X-ray dosage } \\
\circ \quad \text { Radiation therapy } \\
\circ \quad \text { Isotopic tracers } \\
\text { - Subatomic Physics } \\
\end{array}$ \\
\hline
\end{tabular}

